PAULUS, D.; MEDEIROS, S.L.P.; SANTOS, O.S; RIFFEL, C.; FABBRIN, G.; PAULUS, E.. Substratos na produção hidropônica de mudas de hortelã. Horticultura Brasileira, Brasília, v.23, n.1, p.48-50, jan.-mar. 2005.

\title{
Substratos na produção hidropônica de mudas de hortelã
}

\author{
Dalva Paulus ${ }^{1}$; Sandro L.P. Medeiros ${ }^{1}$; Osmar S. Santos ${ }^{1}$; Cinei Riffel ${ }^{2}$; Eliseu G. Fabbrin ${ }^{2}$; Eloi Paulus ${ }^{3}$
}

${ }^{1}$ Universidade Federal de Santa Maria, Depto. Fitotecnia, 97105-900 Santa Maria-RS; ${ }^{2}$ Alunos curso de Agronomia; ${ }^{3}$ Aluno cruso Eng. Florestal E-mail: dalvaufsmdeutch@yahoo.com.br

\section{RESUMO}

O crescimento normal e a formação de plantas com qualidade comercial dependem da produção de boas mudas e para isso, faz-se necessário o uso de um substrato adequado à espécie. A hidroponia mostra-se uma técnica promissora em virtude das vantagens que esse método apresenta: economia de substrato, produção de mudas com alto índice de pegamento e de qualidade. O experimento foi realizado na Universidade Federal de Santa Maria (RS.) com objetivo de avaliar o efeito de substratos (sem substrato, substrato espuma fenólica e substrato organo-mineral), para produção de mudas de hortelã (Mentha x villosa) em cultivo hidropônico através do método de propagação vegetativa por estaquia. $\mathrm{O}$ delineamento experimental foi inteiramente casualizado com três tratamentos e 20 repetições, usando-se uma planta por repetição. As variáveis analisadas foram: número de folhas e altura de planta aos 7; 14; 21 e 28 dias após o transplante, e fitomassa seca e fresca 35 dias após o transplante. O substrato espuma fenólica apresentou os melhores resultados na produção de fitomassa fresca $\left(2,65 \mathrm{~g}\right.$ planta $\left.^{-1}\right)$ e seca $\left(0,23 \mathrm{~g} \mathrm{planta}^{-1}\right)$. Para as demais variáveis analisadas os substratos espuma fenólica e organo-mineral não diferiram significativamente entre si, mas foram superiores ao tratamento sem substrato (direto em solução).

Palavras-chave: Mentha $x$ villosa, plantas medicinais, hidroponia.

\author{
ABSTRACT \\ Mint seedlings assessment of different substrates in \\ hydroponic cultivation
}

The normal growth and the formation of plants with quality for commercialization depends on good seedlings production. The right substrate has to be used. Hydroponic cultivation holds certain advantages: saving substrate, resulting in good establishment of the crop and quality of seedlings production. The experiment was carried out at the University of Santa Maria, Rio Grande do Sul State, Brazil. The effect of substrates (without substrate, phenolic foam substrate and organic-mineral substrates) was determined on the production of mint (Mentha $x$ villosa) transplants by cuttings vegetable methods in hydroponics. The experimental design was a completely randomized design with three treatments and 20 replications, one plant being used in each repetition. We evaluated: height and number of leaves at 7 ; 14; 21 and 28 days after the transplant. Fresh and dry matter weight 35 days after transplant were also analyzed. The phenolic foam substrate showed the best results in relation to the production of fresh and dry matter. Phenolic foam and the organic-mineral substrates were not significantly different, but were significantly superior to the treatment (direct in solution) without substrate.

Keywords: Mentha x villosa, medicinal plants, hydroponics.

\section{(Recebido para publicação em 31 de outubro de 2003 e aceito em 12 de novembro de 2004)}

$\mathrm{V}^{\mathrm{a}}$ árias espécies de Mentha têm sido investigadas, tanto por suas atividades biológicas como também pelos óleos essenciais produzidos por suas folhas. A espécie Menthax villosa é uma planta medicinal e aromática cultivada em todo o Brasil, sendo largamente utilizada pelas indústrias químicas, farmacêuticas e de alimentos.

A hidroponia é uma técnica alternativa de cultivo protegido, na qual o solo é substituído por uma solução aquosa contendo os elementos minerais indispensáveis aos vegetais (Faquim e Furlani, 1999). Ela pode ser usada em regiões com pouca disponibilidade de terras agricultáveis e onde ocorreu o uso excessivo do solo, causando desequilíbrio em sua microfauna, aumentando o nível de infestação de patógenos de solo. Assim, mesmo em países tropicais com abundância de terra como o Brasil, a hidroponia tem sido utilizada com bastante êxito. Além da sua elevada capacidade de produção, independente de clima ou de solo, este sistema de cultivo oferece produtos de alta qualidade com reduzido uso de agrotóxicos, se comparada ao meio tradicional de cultivo no solo (Castellane e Araújo,1995; Junqueira et al.,1997). Praticamente qualquer planta que cresça naturalmente no solo pode ser cultivada em hidroponia. Entre elas, árvores de pequeno porte, arbustos, plantas herbáceas como cereais, leguminosas, plantas ornamentais, hortaliças e outras (Crocomo, 1986). Entretanto, este tipo de cultivo exige cuidados especiais na instalação e condução da cultura. O crescimento normal e a formação de plantas com qualidade comercial dependem da produção de boas mudas. Para isso, alguns fatores devem ser considerados, como: variedade a ser cultivada, origem das sementes, substrato a ser utilizado, local de germinação, crescimento das mudas e manejo do berçário. O substrato influi não só na qualidade das raízes formadas, como também no percentual de enraizamento das estacas (Janick, 1966; Couvillon, 1988), possuindo ainda a função de fixá-las e manter o ambiente, na base das mesmas, úmido, escuro e com adequada aeração (Fachinello et al., 1994). A escolha do substrato depende de suas características físicas e químicas e das exigências da espécie utilizada no enraizamento (Verdonck et al., 1981). As características físicas principalmente relações entre volume de água e ar presentes no substrato, influenciam na morfologia das raízes adventícias formadas e em suas ramificações (Wilson, 1983; Bellé,1990). As técnicas empregadas para produção de mudas utilizam diferentes substratos para o enraizamento de estacas. Em função do tipo de substrato utilizado, as estacas enraizadas podem apresentar desuniformidade das raízes adventícias, refletindo no pegamento e desenvolvimento da planta. 
O substrato exerce influência significativa na arquitetura do sistema radicular e no estado nutricional das plantas (Spurr e Barnes, 1973). O substrato organo-mineral "Plantmax ${ }^{\circledR}$ ", possui boas características físicas, mas necessita da complementação de nutrientes através da aplicação de solução química (Lopes, 1996). Já a espuma fenólica, como inovação tecnológica, é cada dia mais utilizada por apresentar boa capacidade de retenção de umidade, excelente aeração e baixa possibilidade de desintegração no manuseio. Além disso, ocupa pouco espaço e possui baixo custo (Boodley,1984, citado por Martinez e Silva Filho, 1999).

Os estudos de substratos para produção de mudas de menta em hidroponia ainda são escassos. Desta forma, o presente trabalho teve como objetivo avaliar substratos visando a produção de mudas de hortelã (Mentha $x$ villlosa) para cultivo hidropônico, pelo método de propagação vegetativa por estaquia.

\section{MATERIAL E MÉTODOS}

O experimento foi realizado no período de setembro a outubro de $2002 \mathrm{em}$ estufa plástica de $250 \mathrm{~m}^{2}$ coberta com polivinilclorídrico (PVC) com $200 \mu$ de espessura, situada em área experimental da Universidade Federal de Santa Maria, com coordenadas geográficas $29^{\circ} 42^{\prime} \mathrm{S}$ latitude e $53^{\circ} 43^{\prime} \mathrm{W}$ longitude, com $95 \mathrm{~m}$ de altitude. O clima é subtropical úmido com verões quentes, a temperatura média anual é de $19,2^{\circ} \mathrm{C}$ e umidade relativa do ar cerca de 78,4\% em ambiente protegido.

As mudas de hortelã, utilizadas no experimento foram obtidas através do método de propagação vegetativa por estaquia, de matrizes cultivadas em sistema hidropônico. Para o preparo das mudas utilizaram-se estacas do ápice de aproximadamente $3,5 \mathrm{~cm}$ de comprimento e com 3 folhas. Estas, não foram submetidas a nenhum tipo de hormônio de crescimento. O delineamento experimental foi inteiramente casualizado, com três tratamentos e 20 repetições, onde cada repetição foi representada por uma planta. Realizou-se uma leitura por semana, ou seja, aos 7; 14; 21 e 28 dias após transplante (DAT), perfazendo qua-

Tabela 1. Altura de planta por muda de Mentha $x$ villosa cultivada em três substratos. Santa Maria, UFSM, 2002.

\begin{tabular}{lcccc}
\hline \multirow{2}{*}{ Substrato } & \multicolumn{4}{c}{ Altura $(\mathbf{c m})$} \\
\cline { 2 - 5 } & 7 DAT & 14 DAT & 21 DAT & 28 DAT \\
\hline Sem substrato & $4,06 \mathrm{a}^{*}$ & $4,56 \mathrm{a}$ & $9,84 \mathrm{~b}$ & $13,42 \mathrm{~b}$ \\
Espuma fenólica & $3,81 \mathrm{a}$ & $4,63 \mathrm{a}$ & $11,41 \mathrm{a}$ & $19,92 \mathrm{a}$ \\
Organo-mineral & $4,09 \mathrm{a}$ & $4,95 \mathrm{a}$ & $12,81 \mathrm{a}$ & $19,77 \mathrm{a}$ \\
\hline Média & 3,98 & 4,71 & 11,35 & 17,70 \\
\hline C.V.(\%) & 10,40 & 15,77 & 22,81 & 21,45 \\
\hline
\end{tabular}

*Médias seguidas das mesmas letras, nas colunas, não diferem estatisticamente entre si pelo teste de Tukey, a 5\% de probabilidade.

DAT $=$ Dias após o transplante

tro avaliações. Os tratamentos utilizados foram: I) sem substrato (estaca transplantada diretamente em solução nutritiva em berçário); II) substrato espuma fenólica (Green-up ${ }^{\circledR}$ ) e III) substrato organo-mineral Plantmax ${ }^{\circledR}$. No tratamento III foram utilizadas três caixas de madeira (medindo $35 \mathrm{~cm}$ de largura x $75 \mathrm{~cm}$ de comprimento e $10 \mathrm{~cm}$ de altura) para a acomodação de uma camada de $8 \mathrm{~cm}$ de substrato. Já os tratamentos I e II foram conduzidos em berçário, sendo este constituído de 12 tubos de polipropileno com $4 \mathrm{~m}$ de comprimento, $6 \mathrm{~cm}$ de largura e $3 \mathrm{~cm}$ de profundidade colocados sobre cavaletes com desnível de 1\% para escoamento da solução nutritiva. $\mathrm{O}$ espaçamento utilizado entre plantas foi de $0,1 \mathrm{~m}$ x $0,1 \mathrm{~m}$ para todos os tratamentos.

A solução nutritiva foi calculada a partir de dados de produção de fitomassa seca e da quantidade de nutrientes extraídos pela planta (Maia, 1994), e no seu preparo utilizou-se os nutrientes (mg $\left.\mathrm{L}^{-1}\right): \mathrm{K}^{+}=299,52 ; \mathrm{Ca}^{++}=79,60 ; \mathrm{Mg}^{++}$

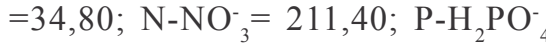
$=27,90 ; \mathrm{S}_{-} \mathrm{SO}_{4}^{-}=11,84 ; \mathrm{B}=2,844$; $\mathrm{Cu}=0,075 ; \mathrm{Mn}=6,084 ; \mathrm{Mo}=0,0883$; $\mathrm{Zn}=\quad 0,431 ; \quad \mathrm{FeSO}_{4}^{-}=6,08$; $\mathrm{Na}_{2}$ EDTA $=14,890$. Esta, foi diluída a $50 \%$ da concentração original, conforme recomendado por Furlani (1998) para a fase de produção de mudas.

Para o armazenamento da solução nutritiva, utilizou-se reservatório de fibra de vidro com capacidade de 400 litros. O controle da circulação da solução foi realizado com o auxílio de temporizador programado para acionar a moto-bomba durante 15 minutos, com intervalos de 15 minutos, no período das 07:00 às 20:00 horas, e 15 minutos a cada intervalo de 2 horas no período das 20:00 às 07:00 horas. O manejo da solução foi realizado a cada dois dias através da reposição da água consumida e do monitoramento da condutividade elétrica e correção do $\mathrm{pH}$.

As variáveis analisadas foram altura das mudas, número de folhas, fitomassa fresca e seca. A determinação da fitomassa foi realizada aos 35 DAT, onde se utilizou as folhas e as hastes da planta que, posteriormente, foram colocadas em estufa com circulação de ar forçada a $65^{\circ} \mathrm{C}$ para obtenção da massa seca. Os dados foram submetidos à análise da variância, sendo as médias testadas pelo teste de Tukey a 5\% de probabilidade de erro.

\section{RESULTADOS E DISCUSSÃO}

Para altura das mudas (Tabela 1) aos 7 e 14 dias após transplante (DAT), verificou-se que não houve diferença estatística entre os tratamentos. Já aos 21 e 28 DAT, observou-se desempenho diferenciado entre os substratos, sendo que os tratamentos espuma fenólica e organo-mineral não diferiram estatisticamente entre si, contudo, mostraramse superiores ao tratamento sem substrato (direto em solução). Com relação às médias do tratamento, observa-se evolução no ganho em altura, sendo que na fase inicial obteve-se um acréscimo de $0,73 \mathrm{~cm}$ aos 14 DAT, 6,64 $\mathrm{cm}$ aos 21 DAT e $6,35 \mathrm{~cm}$ aos 28 DAT.

Verificou-se que não houve diferença estatística entre o número de folhas (Tabela 2), aos 7 DAT, porém aos 14 DAT observou-se desempenho diferenciado entre os substratos, sendo que os tratamentos espuma fenólica e organo- 
Tabela 2. Número de folhas por muda de Mentha $x$ villosa cultivada em três substratos. Santa Maria, UFSM, 2002.

\begin{tabular}{llccl}
\hline \multirow{2}{*}{ Substrato } & \multicolumn{4}{c}{ Número de folhas } \\
\cline { 2 - 5 } & 7 DAT & 14 DAT & 21 DAT & 28 DAT \\
\hline Sem substrato & $4,70 \mathrm{a}^{*}$ & $5,70 \mathrm{~b}$ & $8,90 \mathrm{c}$ & $12,25 \mathrm{~b}$ \\
Espuma fenólica & $4,90 \mathrm{a}$ & $6,85 \mathrm{a}$ & $12,50 \mathrm{a}$ & $15,60 \mathrm{a}$ \\
Organo-mineral & $4,50 \mathrm{a}$ & $7,05 \mathrm{a}$ & $11,10 \mathrm{~b}$ & $13,40 \mathrm{~b}$ \\
\hline Média & 4,70 & 6,53 & 10,83 & 13,75 \\
\hline C.V.(\%) & 20,51 & 21,04 & 14,3 & 14,07 \\
\hline
\end{tabular}

*Médias seguidas das mesmas letras, nas colunas, não diferem estatisticamente entre si pelo teste de Tukey, a $5 \%$ de probabilidade.

DAT $=$ Dias após o transplanta

Tabela 3. Fitomassa fresca e seca $\left(\mathrm{g}_{\text {planta }}{ }^{-1}\right)$ de mudas Mentha $x$ villosa cultivada em três substratos, obtidos 35 dias após o transplante. Santa Maria, UFSM, 2002.

\begin{tabular}{lcc}
\hline Substrato & Massa fresca $\left(\right.$ g planta $\left.^{-1}\right)$ & Massa seca (g planta- $\left.{ }^{-1}\right)$ \\
\hline Sem substrato & $1,49 \mathrm{c}^{*}$ & $0,14 \mathrm{~b}$ \\
Espuma fenólica & $2,65 \mathrm{a}$ & $0,23 \mathrm{a}$ \\
Organo-mineral & $2,25 \mathrm{~b}$ & $0,16 \mathrm{~b}$ \\
\hline $\mathrm{C}$ V $(\%)$ & 23,37 & 24,49
\end{tabular}

*Médias seguidas das mesmas letras, nas colunas, não diferem estatisticamente pelo teste de Tukey, a $5 \%$ de probabilidade.

mineral não diferiram estatisticamente entre si, contudo, mostraram-se superiores ao tratamento sem substrato (direto em solução). Aos 21 e 28 DAT, o substrato espuma fenólica foi o melhor tratamento. Verificou-se acréscimo do número de folhas nos intervalos de tempo avaliados, sendo de 1,83 aos 14 DAT, 4,3 aos 21 DAT e 2,92 aos 28 DAT.

$\mathrm{Na}$ produção de fitomassa fresca observou-se que o substrato espuma fenólica foi superior aos demais tratamentos (Tabela 3), verificando-se o mesmo na produção de fitomassa seca; as mudas produzidas em substrato espuma fenólica produziram $0,7 \mathrm{~g} \mathrm{planta}^{-1}$ a mais que quando do uso do substrato organomineral aos 35 DAT. Os tratamentos sem substrato e organo-mineral, não diferiram estatisticamente entre si. Os resultados obtidos se justificam, pois o substrato espuma fenólica possui retenção e absorção controlável da umidade, evitando, problemas degenerativos no sistema radicular. Além disso, proporciona maior suporte à estaca, o que aliado à ausência de estresse pós-transplante, permite enraizamento rápido e melhor desenvolvimento da planta. Resultados semelhantes foram alcançados em trabalho realizado na cultura do morangueiro por Andriolo e Bonini (1999).
Matias et al. (1999), em trabalhos de avaliação de substratos comerciais para produção de mudas de alface, constataram ser a espuma fenólica o substrato mais adequado para o cultivo hidropônico, principalmente aos 11 dias após o início da germinação. Esses resultados estão de acordo com a proposta do IAC para a utilização de espuma fenólica na produção de mudas pelos produtores que trabalham em hidroponia (Furlani, 1998).

Lira (1990), estudando efeitos de substrato e do superfosfato simples na produção de mudas de limoeiro até a repicagem, concluiu que o substrato organo-mineral Plantmax ${ }^{\circledR}$ proporcionou melhores características de fertilidade e teores de nutrientes na fitomassa seca total das plantas e maior crescimento do limoeiro "Cravo", quando comparado com tratamentos à base de um Latossolo Vermelho Amarelo húmico misturado com Latossolo Roxo e vermiculita. Resultados semelhantes foram obtidos por Lopes (1996), em trabalho de propagação sexuada de mudas de maracujazeiro em tubetes, com uso de substratos e doses de adubação nitrogenada, concluiu que o substrato organo-mineral Plantmax ${ }^{\circledR}$ proporcionou melhor desenvolvimento das mudas em comparação com os outros utilizados, com as composições: a) $70 \%$ de vermiculita $+30 \%$ de ter- ra de subsuperfície; b) $40 \%$ de casca de arroz carbonizada $+30 \%$ de terra de subsuperfície $+30 \%$ de areia.

Considerando os resultados obtidos, o substrato espuma fenólica pode ser recomendado para produção de mudas de menta em cultivo hidropônico.

\section{LITERATURA CITADA}

ANDRIOLO, A.L.; BONINI, J.V. Resultados preliminares sobre o cultivo do morangueiro em substratos. Santa Maria: Centro de Ciências Rurais, 1999. 5 p. (Informe Técnico, n.5)

BELLÉ, S. Uso da turfa "Lagoa dos Patos (Viamão/RS). 1990. 142 f. (Tese mestrado) UFRGS, Porto Alegre.

CASTELANE, P.D., ARAÚJO, J.A.C. Cultivo sem solo-hidroponia. Jaboticabal: FUNEP, 1995. 43 p. COUVILON, G.A. Rooting responses to different treatments. Acta Horticulturae, v.227.p.187-196. 1988. CROCOMO, O.J. Cultivo fora do solo: hidroponia. In: MAGALHÃES, A.; BORDINI, M.E. (Ed.) Grande manual globo de agricultura, pecuária e receituário industrial. Porto Alegre: v.3. p.209-220. 1986.

FACHINELLO, J.C.; HOFFMANN, A. ; NACHTGAL, J.C. Propagação de plantas frutiferas de clima temperado. Pelotas: UFPEL, 1994. 179 p.

FAQUIN, V.; FURLANI, P. R. Cultivo de hortaliças de folhas em hidroponia em ambiente protegido. Informe Agropecuário, Belo Horizonte, v.20. n.200/201. p.99-104. Set./dez. 1999.

FURLANI, P.R. Instruções para o cultivo de hortaliças de folhas pela técnica de hidroponia. Campinas: Instituto Agronômico, 1998. 30 p.

JANICK, J. A ciência da horticultura. Rio de Janeiro: USAID, 1966. 485 p.

JUNQUEIRA, A.M.R.; LIMA, J.A.; PEIXOTO, J.R. Hidroponia: cultivo sem solo. Brasília: UNB, Curso de Extensão da Faculdade de Agronomia e Medicina Veterinária, 1997. 31 p.

LIRA, L.M. Efeito de substratos e do superfosfato simples no limoeiro (Citrus limonia OSBECK cv. cravo) até a repicagem. 1990. 86 f. (Tese mestrado) - ESAL, Lavras.

LOPES, P.S.N. Propagação sexuada do maracujazeiro azedo (Passiflora edulis Sims f. favicarpa Deg.) em tubetes: efeito da adubação nitrogenada e substratos. Lavras: UFLA, 1996. 52 f. (Tese mestrado). MAIA, N.B. Nutrição mineral, crescimento e qualidade do óleo essencial da menta (Mentha arvensis L.) cultivada em solução nutritiva. 1994 69 f. (Tese mestrado) - USP, ESALQ, Piracicaba. MARTINEZ, H.E.P.; SILVA FILHO, J.B. Substratos para Hidroponia. Informe Agropecuário, Belo Horizonte, v.20. n.200/201. p.81-89. 1999. MATIAS, G.C.S.; COMETTI, N.N.; GÓMEZ, G.P.; ROCHA, J.D.S. Avaliação de substratos comerciais para a produção de mudas de alface. Horticultura Brasileira, Brasília, v.17. n.2. p.159-162. 1999.

SPURR, S.H.; BARNES, B.V. Forest ecology. New York: The Ronald Press, 1973. 571 p.

VERDONCK, O.; VLEESCHAUWER, D.; BOODT, M. The influence of the substrate to plant growth. Acta Horticulturae, v.126. p.251-258. 1981. WILSON, G.C.S. Use of vermiculite as a growth medium for tomatoes. Acta Horticulturae, v.150. p.283-288. 1983. 